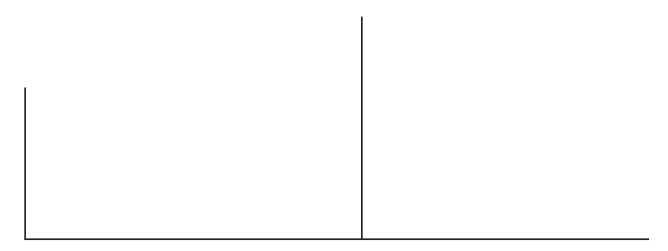

Rev. Latinoam. Psicopat. Fund., IV, 1, 76-85

\title{
Angústia e violência: sua incidência na subjetividade*
}

\author{
Analuiza Mendes Pinto Nogueira
}

\begin{abstract}
Este texto indaga se a angústia pode gerar atos de violência, quando não encontra vias de simbolização.

O problema é investigado a partir do exame dos modos de subjetivação de crianças e jovens com história de abandono elou práticas de violência, e sua discussão, por meio de um caso clínico, aborda os prejuízos decorrentes da ruptura precoce dos laços familiares, que reinstala o desamparo, e da perda da função paterna, que implica um déficit simbólico e instaura a tendência para "agir as pulsões".
\end{abstract}

Palavras-chave: Psicanálise, angústia, violência, subjetividade, estudo de caso

* Esta é uma pesquisa integrada aos estudos do Grupo de Trabalho Psicopatologia e Psicanálise da Associação Nacional de Pesquisa e Pós-Graduação em Psicologia (ANPEPP), cujo tema, apresentado no VIII Simpósio Brasileiro de Pesquisa e Intercâmbio Científico (Serra Negra, São Paulo, maio de 2000), foi “A angústia”. 


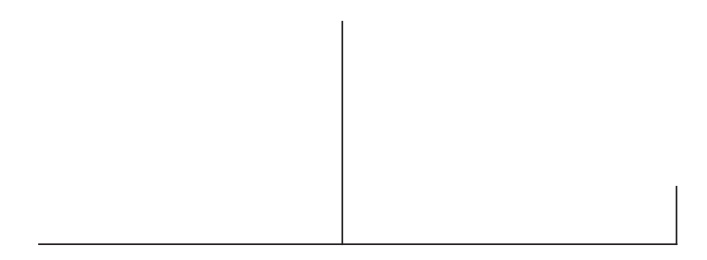

A violência generalizada vivida pela humanidade nos tempos atuais é objeto de preocupação no recorte que escolhemos fazer no estudo da problemática da angústia, violência que não se encontra apenas nas ruas, mas também nas instituições e dentro dos lares, e que não tem uma única cara, mas se transveste em formas variadas, como abandono, agressão, roubo, assassinato, suicídio...

Violência praticada, violência sofrida, violência auto-infligida... A violência parece estar presente em cada canto da vida. Se atentamos para o ensinamento de Freud em "Totem e tabu" e "O mal-estar na cultura" (1913 e 1930), temos de admitir, sobretudo, que a violência está presente no ato inaugural da civilização humana, onde têm lugar o crime primordial, o parricídio e o conflito fratricida. Comparece, igualmente, no ato original do próprio homem, porquanto o constitui mediante um acontecimento traumático, a separação da mãe, que o lança no estado de desamparo (Freud, 1926). Essas duas condições fundadoras, que se inscrevem na trajetória de cada um, no seu advento como sujeito psíquico, selam definitivamente o mal-estar subjetivo. A articulação entre violência e angústia, numa primeira aproximação, pode ser relacionada a esses momentos míticos, à violência do ato de nascimento da cultura e da subjetividade, fontes da angústia fundamental do homem.

Nossa pesquisa procura investigar as relações possíveis entre angústia e violência, formulando uma indagação central: podemos entender a angústia como geradora de atos de violência?

Uma das vias estabelecidas para tratar o problema que nos colocamos foi o exame dos modos de subjetivação de crianças e jovens com história de abandono e/ou práticas de violência, entendendo que tais circunstâncias possam ter um efeito comprometedor na constru- 
ção do Eu, deixando o sujeito exposto à angústia de aniquilação e favorecendo as ações defensivas destrutivas.

Para tanto, adotamos o método clínico de investigação e, tomando a psicanálise como referência teórica, empenhamo-nos em fazer uma escuta psicanalítica dos sujeitos, em variadas situações de seu cotidiano. Foram utilizadas conversas espontâneas, observações informais, desenhos e entrevistas, para construção das histórias de vida. Estas, por sua vez, não constituem histórias biográficas, mas "estórias" que cada um constrói para si, emprestando-lhes valor de realidade, e que nos conta como forma de falar sobre si mesmo e de dar sentido à sua existência.

\section{Sobre as teorias freudianas da angústia}

Em Freud, podemos encontrar duas diferentes teorias sobre a angústia, das quais queremos sublinhar, em linhas gerais, os eixos principais que nortearão aqui nosso entendimento sobre o conceito. A primeira delas, uma concepção econômica (Freud, 1950), concebe a angústia como energia sexual (libido) não elaborada, ou seja, desligada das representações. A angústia é, então, referida a uma experiência afetiva de caráter desprazeroso e desprovida de significação, um acúmulo de excitação que não encontra via adequada de escoamento para a satisfação, o que quer dizer que não encontra seu correspondente simbólico. Se há excesso de tensão, por um lado, explicita Laplanche (1987), há escassez do lado psíquico, visto que a tensão não é descarregada por meio da atividade representativa. Assiste-se ao que o autor chama de ausência de psiquisação, de simbolização ou fantasmatização.

A segunda teoria, de natureza funcional, vem a ser sistematizada um tanto tardiamente, em 1926, com o importante texto "Inibição, sintoma e angústia", já dentro do quadro teórico da chamada "segunda tópica" freudiana. Neste momento da construção teórica de Freud, a angústia é definida como um sinal, uma reação, preparação do Eu para um perigo, remontando, o perigo de que se trata, a uma situação primordial da vida do ser humano, a separação da mãe.

A separação da mãe, no ato do nascimento, representa a situação que dá origem à angústia e se constitui como protótipo para todo e qualquer estado de angústia posterior experimentado pelo sujeito. Se se refere ao estado real do desamparo (Hilflosigkeit) em que é lançado o recém-nascido, com o incremento das excitações e sensações físicas de desprazer, também aponta para o perigo psíquico, pulsional, vinculado às exigências da libido. A ameaça de perigo interno, diz-nos Freud, é vivida pelo Eu como se se tratasse de um perigo externo.

O texto publicado em 1917, a conferência sobre a angústia, em que discute questões como as citadas, tem um caráter integrador das duas teorias, pois já an- 


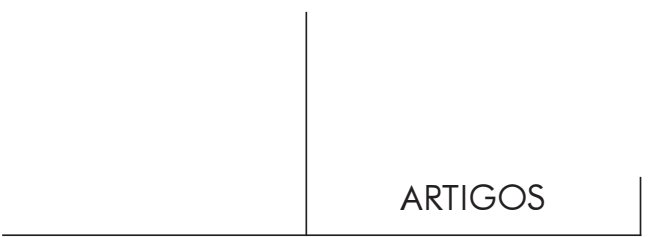

tecipa as novas posições que serão formuladas em 1926. Esse texto é interessante também por trazer outros pontos importantes para o que aqui nos ocupa. Nele, Freud afirma, por exemplo, que "geralmente, a reação a um perigo é um composto de sentimento de angústia e ação defensiva" e acrescenta, mais adiante, ao falar da angústia na histeria, que o complemento inconsciente do estado de angústia pode ser tanto "uma excitação positivamente libidinosa ou um sentimento hostil, agressivo, como o furor ou a cólera" (Freud, 1917: 2368 e 2374, respectivamente; os grifos são nossos).

Admitindo, pois, que a angústia é reação a um perigo pulsional que ameaça o Eu, e que tal reação comporta uma ação defensiva, fica estabelecido um elo importante entre angústia e violência, posto que essa defesa pode ser acompanhada de sentimentos hostis e agressivos.

Podemos, contudo, melhor precisar nossa questão inicial, dizendo que a angústia pode gerar atos de violência, porquanto não encontra possibilidade de simbolização. Se o que ameaça o Eu diz respeito a um perigo diante de algo excessivo e não elaborável pelos processos do pensamento, esse inominável, impossível de dizer, se faz ato. Agieren é o termo alemão utilizado por Freud, tendo um sentido transitivo, o de "agir pulsões", e opondo-se ao recordar, atividade da esfera psíquica, ligada aos processos simbólicos (Laplanche e Pontalis, 1985: 36).

\section{Angústia e violência em situação de desamparo}

Retornemos ao que é, em psicanálise, o protótipo de toda angústia - a separação da mãe no ato de nascimento, uma experiência tóxica, caracterizada pela ausência de psiquisação, e que instala o desamparo. O estado afetivo de angústia constitui a repetição desse acontecimento arcaico.

Da perspectiva do nascimento psíquico do ser humano, a violência é marcada pelo ataque da pulsão. Esta, corpo estranho interno implantado pelo outro no cuidado maternal, o qual é carregado de mensagens enigmáticas, sexuais e inconscientes (Laplanche, 1992), transborda em excesso de excitação, sem que seja possível ainda sua ligação à palavra, que porta o sentido. Assim compreendemos como a sexualidade nascente é traumática, como a subjetividade se constitui mediante a violência do desejo do outro.

O Eu que deve advir da relação primordial, em cujo seio se constitui a função materna, que ampara e suporta a carência fundamental do sujeito, deve tomar a si a tarefa de defender-se ante as tensões pulsionais, utilizando-se dos processos de simbolização. Mas a cada vez que o sujeito é inundado pelas forças pulsionais, incapaz de significá-las, reestabelece-se o sentimento de desamparo e o Eu é novamente invadido pela angústia. 


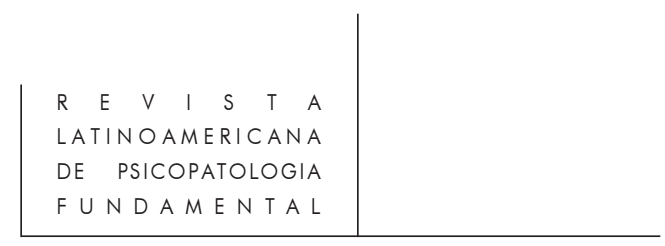

As situações de privação (Winnicott, 1987), como as decorrentes de rupturas precoces dos laços familiares são, assim, situações que perpetuam o desamparo, deixando o sujeito abandonado aos próprios impulsos, cujo efeito é a reinstalação da angústia. Se o agir as pulsões é uma saída possível para o estado angustioso, e pode se fazer por meio de atos agressivos e violentos, somos levados a considerar uma outra circunstância ligada ao processo de subjetivação - a função paterna - a qual está aí implicada.

Alguns autores já têm apontado para a ausência do pai como fator que desempenha importante papel na determinação dos atos infracionais de menores (Berlinck, 1991; Goldenberg, 1998; Marin, 2000, entre outros). Quanto a isso, explicam que a insuficiência da figura paterna abre espaço para a transgressão e a não valorização da lei, na medida em que é por meio do pai que a criança dela toma conhecimento. Com efeito, a função castradora do pai simbólico, sendo aquela que interdita o desejo infantil, onipotente e narcísico, é o que permite a identidade da criança, inserindo-a numa linha de afiliação, estabelecendo limites, indicando ideais coletivos a serem preservados.

A falência do Nome-do-Pai, em seu valor significante, parece comprometer, ademais, a aquisição pela criança dos processos simbólicos. Esse déficit simbólico se faz notar na tendência a agir, sempre que haja acúmulo de excitação pulsional, ou seja, sempre que o sujeito seja tomado pela angústia, em ocasiões como as de abandono e perda, de perigo e medo, em que é reconduzido à experiência de desamparo.

Freud é enfático ao declarar que o Eu é o lugar da angústia (Freud, 1926). Afirma, ainda, que o perigo ao qual o Eu busca escapar se refere às exigências da libido, mas que a angústia é projetada no exterior e elaborada, secundariamente, como angústia de morte, que a realidade legitima, particularmente no caso dos sujeitos de nosso estudo. Contudo, essa angústia ante o aniquilamento do Eu tem também, a nosso ver, o sentido de desvalimento do Eu, quer dizer, ameaça da destruição narcísica do Eu.

\section{Fragmentos de uma história clínica}

Ouvir crianças e jovens abandonados e/ou infratores, com o intuito de explicitar as relações possíveis entre angústia e violência, faz sentido se consideramos que os modos particulares de subjetivação a que se acham submetidos favorecem a instalação de situações de desamparo, bem como a debilidade da função paterna, uma vez que esses sujeitos são oriundos de determinados segmentos da sociedade, caracterizados pela desagregação familiar e pela carência extrema dos meios de trabalho e dos modos de subsistência em geral. Entendemos que os modos de 


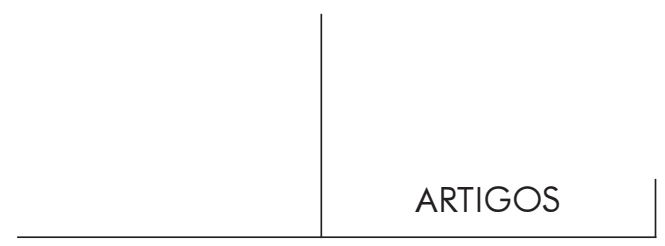

subjetivação dizem respeito aos processos formadores do Eu e da identidade pessoal, o que inclui, entre outros, as identificações do sujeito, a imagem que constrói de si mesmo, suas referências parentais, história passada, projetos futuros etc.

Nossa suposição é que tais modos de subjetivação, na medida em que reproduzem o estado de desamparo, podem comprometer a constituição do sentido do $\mathrm{Eu}$, deixando o sujeito exposto à angústia. Por outro lado, ante a angústia, a insuficiência de elaboração simbólica por parte do sujeito, ligada à carência da função paterna, tende a levá-lo à ação.

Em síntese, estes menores se encontram em situações propícias à recorrência de estados de angústia constantes e severos, o que vem facilitar as soluções pela violência.

A amostra estudada é composta pelos internos das casas de recolhimento do Juizado da Infância e da Juventude de Fortaleza, que mantém diferentes programas de atendimento a menores, desde o abrigo em creches até as unidades de reclusão. Passamos a apresentar, num relato breve, um caso clínico por meio do qual podemos ilustrar o que vimos discutindo. Inicialmente, abordaremos algumas questões relacionadas à história de vida do paciente, da maneira como foi construída em análise, e à constituição de sua subjetividade. Em seguida, trataremos mais especificamente de alguns aspectos de sua história clínica, ligados à angústia e ao "agir as pulsões", na forma de auto-agressão conforme se apresentou neste caso $^{1}$.

\section{A perda das referências parentais tem efeito nocivo no estabelecimento da identidade}

Paulo 2 é uma criança de nove anos de idade, que ficou órfão aos cinco, quando seus pais foram assassinados, e que vive no Abrigo de Crianças de Fortaleza.

A vida dessa criança é marcada por grandes perdas, seja a morte brutal, num curto espaço de tempo, dos dois pais, seja a separação dos seus três irmãos, cada um sendo levado para lares de parentes distintos. Paulo ficou sob a guarda de um tio materno que, decorridos seis meses, veio a falecer. Depois disso, restou-lhe a casa da tia, de onde fugiu ante a exploração e os maus tratos sofridos. Da rua para a guarda institucional não demorou muito.

As referências parentais são decisivas para a subjetividade humana. Não só a imagem corporal, a sustentar o sentimento de si mesmo, como também os objetos

1. Caso atendido na Clínica Escola de Psicologia da Universidade Federal do Ceará, pela estagiária Ana Carolina Gadelha Pereira da Silva, sob supervisão da autora.

2. O nome do paciente é fictício. 


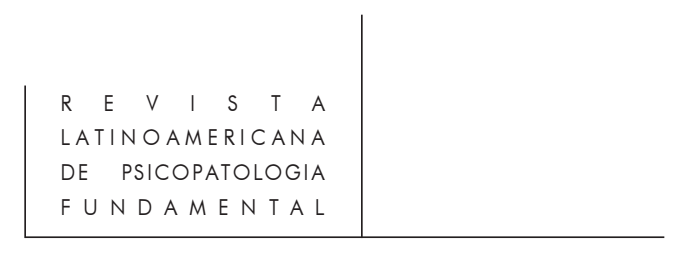

identificatórios, valores e papéis reservados pela cultura para cada sujeito, que deles deverá se apropriar, são possibilitados pela mediação dos vínculos parentais. O desenraizamento sofrido pela criança abandonada deixa-a desprovida dos significantes básicos sobre os quais possa projetar-se como um sujeito no mundo.

Um dos elementos centrais que dão ao sujeito o referencial sobre ele mesmo é o nome próprio, este que é vivido como sendo Eu e que tem uma função mediadora entre o corpo e o mundo socializado da linguagem (Martins, 1991). Segundo este autor, se o prenome identifica o sujeito como uma pessoa singular, o sobrenome o inscreve na diferença das gerações, cumprindo uma função simbólica com referência à lei edípica. Contudo, é necessário que o sujeito se aproprie do nome para torná-lo próprio.

Paulo, no entanto, esquecera os nomes dos pais e até os dos irmãos. Nem ao menos sabia dizer o seu nome completo. Quem é Paulo?

A perturbação decorrente da perda do patronímico se liga à construção de uma imagem ambígua e pouco consistente de si mesmo, imagem que se transmuda radical e inesperadamente no seu oposto. Uma circunstância exemplar, quanto a isso, se refere à brincadeira de polícia e ladrão, tão repetida pela criança nas sessões clínicas, quando armava-se com o distintivo e todo o arsenal de policial, para no instante seguinte bater-se com o cacetete e prender-se com as algemas: "Agora eu sou o ladrão", diz ele.

Entre o "bonzinho" e o "danado", ele se define: "Eu tenho duas caras". Desenha sua própria máscara, recorta e passa a usá-la, denotando com este movimento a alienação a que está submetido e a hesitação que marca a escolha entre os traços identificatórios com figuras protetoras idealizadas, de um lado, e figuras muito degradadas, de outro.

A história familiar de Paulo permite-nos indicar certos elementos em jogo nesse processo identificatório. Um pai alcoólatra, assassinado por um policial numa briga de bar e traído pela mulher ("Meu pai era triste, porque a mãe dormia com outros homens", declara). A mãe, "a mais esperta", segundo sua visão, é morta por um dos amantes ("Minha mãe morreu porque tinha homens", confessa ele). Há ainda o irmão mais velho, fazendo carreira no crime, pelas ruas de São Paulo ("Já deve estar preso, porque ele rouba", diz a criança).

O universo dessa criança é feito de "danação" - vício, roubo, traição - cujo resultado mais certo é a morte. Poderá o Eu se estabelecer e se guiar por ideais pessoais, familiares e sociais, que lhe garantam um destino menos trágico? A história de Paulo atesta que "o menor abandonado não tem pai", no sentido em que o afirma Berlinck (1988: 33), ou seja, que o pai, mesmo presente, não consegue desempenhar as funções de pai, por ser, antes, um pai degradado. Se há prejuízo no acesso ao simbólico e na submissão aos imperativos da lei, este é também um pre- 


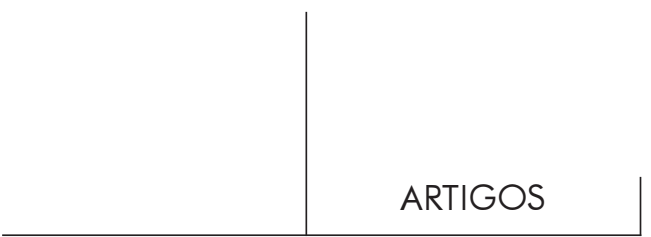

juízo narcísico, ligado à fragilidade da formação do Ideal de Eu ("Eu nasci triste, sou triste como meu pai, sou triste porque não tenho pai nem mãe", afirma ele). Não nos surpreende que, não havendo o deslocamento das posições narcísicas mais primitivas, a criança permaneça na ilusão do Eu Ideal, submetida à tirania das soluções onipotentes, entre as quais a violência.

A angústia vivida por Paulo aponta para um perigo narcísico, sendo o sinal da falência do projeto egóico, que se traduz na sua desesperança quanto ao futuro: "Não tenho mais para onde ir".

\section{O sujeito tende a agir as pulsões quando não encontra palavra para significá-las}

Paulo chega à consulta por apresentar comportamentos de rebeldia e automutilação. Nas entrevistas iniciais a queixa vai se estabelecendo, referindo-se a uma grande instabilidade no humor e na conduta da criança que, com frequiência, se torna extremamente agitada, ocasião em que é levada a destruir objetos e a apresentar comportamento agressivo com as pessoas. Além disso, costuma machucar-se a si mesma, chegando a ferir-se.

O espaço terapêutico, possibilitando-lhe falar de sua dolorosa história, promove a simbolização dos impulsos, fazendo ceder a angústia sem nome que a afeta.

Com efeito, as histórias criadas para as personagens de suas brincadeiras encenam, pela estreita semelhança, a sua própria história: são todas crianças ameaçadas pela morte e pelo abandono. Ele representa, por meio do brincar, uma imagem de si mesmo que evoca seu desamparo: "Uma criança está doente. O pai tem que cuidar dela, não pode viajar".

A partir da queixa e da demanda de alívio, a promessa de um sentido possível começa a se delinear. A oferta de simbolização, de acesso a uma significação a partir do que se apresenta como sofrimento, traz como efeito o apaziguamento do afeto em excesso, que parece colocar o sujeito numa situação similar ao desamparo (Pereira, 1999, citado por Besset, 2000, p. 9).

É preciso, então, colocar em palavras, ademais, o sentimento subjacente à recusa de ir para a escola e aos impulsos incontidos de rasgar seus livros e roupas, dando um sentido a tais atos: "Tenho muita raiva das crianças que [na escola] choram com saudade dos pais. Tenho muita raiva dos que vão para casa todo dia com seus pais". A escola, lembrando-lhe a ausência dos pais, se torna um dos objetos sobre os quais a angústia facilmente se projeta. Todavia, dando um nome ao seu medo, é possível a Paulo retornar às atividades escolares.

Enquanto está desligada das palavras, a angústia toma o caminho do corpo. O corpo é o lugar em que se inscreve o excesso, o resto de libido não utilizada. 


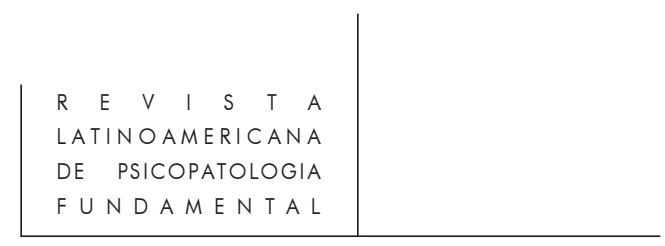

Corpo fragmentado, objeto parcial, que não está organizado num todo, guardando o sentido do Eu. É um corpo de certa forma alheio a ele mesmo e, por isso, pode ser flagelado. Corpo depositário de um gozo descomedido: conta que, certa vez, doente, com o corpo cheio de lesões decorrentes da catapora, jogou-se na areia fazendo infeccionar as feridas e tornando mais dolorosa a doença e mais morosa a cura.

Paulo chega à sessão, repetidas vezes, queixando-se de dores: dor na coluna, dor no pé... Chega com o dedo cortado, a mão ferida, com marcas espalhadas por diversas partes do corpo. Quando o significante doente é pontuado, Paulo passa a produzir um discurso em que, incansavelmente, fala de meninos doentes, que sofrem, que precisam de médicos, de pai, de colo de mãe, que precisam ser cuidados... assim como ele. Produz, com isso, um saber, tornando dispensável o sintoma, o de machucar-se para localizar na dor da ferida o seu sofrimento e desamparo.

Em síntese, podemos dizer que a angústia e a violência incidem na subjetividade pela carência associada às funções maternas e paternais. Será pela palavra que o sujeito poderá atribuir significação a esta falta, que constitui o sintoma mudo - a angústia - e, fazendo-o falar, substituirá a ação pelo verbo.

\section{Referências Bibliográficas}

BerLINCK, M. T. Alexandre e seus irmãos: psicanálise de pixotes?. In Psicanálise da clínica cotidiana. São Paulo: Escuta, 1988, pp. 23-42.

Besset, V. A clínica da angústia: um lugar para o sujeito. Trabalho apresentado na XXX Reunião Anual de Psicologia, Brasília, Distrito Federal, 2000.

Freud, S. Obras Completas. $4^{\mathrm{a}}$ ed. Madrid: Biblioteca Nueva, 1981.

(1913). Totem y tabu. O.C. Op. cit. v. II.

(1917). Lecciones introductorias al psicoanálisis. (La angustia). O.C. Op. cit. v. II. (1926). Inhibicion, sintoma y angustia. O.C. Op. cit. v. III.

(1930). El malestar en la cultura. O.C. Op. cit. v. III.

(1950). Los origenes del psicoanálisis. (Manuscrito E - Cómo se origina la angustia). O.C. Op. cit. v. III.

GolDENBERG, G. W. O pai simbólico está ausente na criança e no adolescente infratores. In Levisky, D. L. Adolescência - pelos caminhos da violência. São Paulo: Casa do Psicólogo, 1998, pp. 113-28.

Laplanche, J. \& Pontalis, J.-B. Vocabulário da psicanálise. São Paulo: Martins Fontes, 1985.

Laplanche, J. A angústia. São Paulo: Martins Fontes, 1987.

. Novos fundamentos para a psicanálise. São Paulo: Martins Fontes, 1992.

MARIN, I. S. K. Sujeito - desamparo e violência. Trabalho divulgado pela Internet para apresentação nos Estados Gerais da Psicanálise, Paris, França, 2000. 


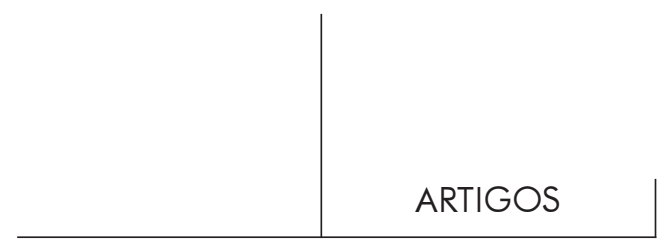

Martins, F. O nome próprio. Brasília: Editora Universidade de Brasília, 1991.

Winnicott, D. W. Privação e delinqüência. São Paulo: Martins Fontes, 1987.

\section{Resumos}

Este texto indaga si la angustia puede generar actos de violencia, cuando no encuentra vías de simbolización.

El problema es investigado desde el examen de los modos de subjetivación de niños y jovenes con historia de abandono y/o practicas de violencia, y su discusión, a traves de un caso clinico, aborda los perjuicios de la rotura precoz de los lazos familiares, que reinstala el desamparo, y de la perdida de la función paterna, que implica un déficit simbólico e instaura la tendencia para "obrar las pulsiones".

Palabras llave: Psicoanálisis, angustia, violencia, subjetividad

Ce texte interroge si l'angoisse peut générer actes de violence, quand ne trouve pas voies de symbolization.

Le probléme c'est étudié depuis l'examen des moyens de subjetivations d'enfants et jeunes avec histoire d'abandon et/ ou practiques de violence, et la discussion, à travers d'un cas clinique, aborde les préjudices de la rupture précoce des liens familiers, que reinstalle l'abandon, et de la perte de la function paterne, qu'implique un déficit symbolique et institue la tendance pour "agir las pulsions".

Mots clés: Psychanalyse, angoisse, violence, subjectivité

This text is a discussion about whether anxiety can be the cause of acts of violence, when the anxiety finds no channel for symbolization.

The problem is approached by studying the manners of subjectivation of children and young people with histories of neglect and/or practices of violence. The problem is discussed on the basis of a clinical case. The article also treats of the damages that result from the breakage of family ties early in life, a fact which reinstalls feelings of helplessness and the loss of the father function, implying symbolic deficit and establishing a tendency to "act out the drives."

Key words: Psychoanalysis, anxiety, violence, subjectivity, case study

Versão inicial recebida em dezembro de 2000

Versão revisada recebida em fevereiro de 2001 